\title{
Erratum
}

\section{Low Resilience of the Particle-Attached Bacterial Community in Response to Frequent Wind-Wave Disturbance in Freshwater Mesocosms}

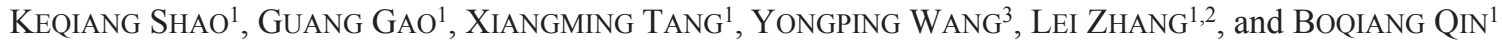 \\ ${ }^{1}$ State Key Laboratory of Lake Science and Environment, Nanjing Institute of Geography and Limnology, Chinese Academy of \\ Sciences, 73 Beijing East Road, Nanjing 210008, China; ${ }^{2}$ Graduate School of Chinese Academy of Sciences, Beijing 100039 , \\ China; and ${ }^{3}$ State Key Laboratory of Hydrology-Water Resources and Hydraulic Engineering, Nanjing, 223 Guangzhou Road, \\ Nanjing 210029, China
}

Volume 28, no. 4, Page 450-456, 2013

Page 450

Date of "Published online" is incorrect. It should be corrected as follows:

incorrect: November 26, 2013

correct: December 13, 2013

This correction has been completed on the electronic file of the present paper available at J-STAGE.

The editorial board expresses sincere apology for the misprinting. 